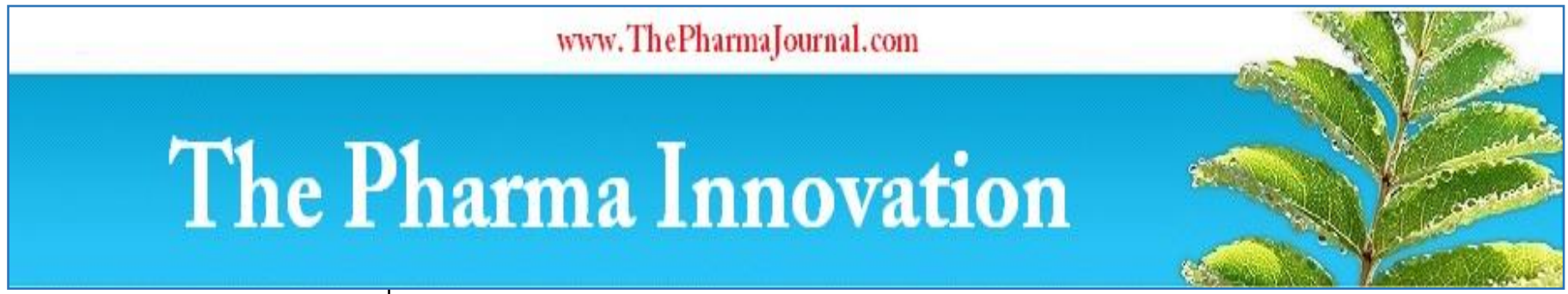

ISSN (E): $2277-7695$

ISSN (P): 2349-8242

NAAS Rating: $\mathbf{5 . 0 3}$

TPI 2021; 10(2): 196-199

(C) 2021 TPI

www.thepharmajournal.com

Received: 16-11-2020

Accepted: 13-01-2021

Ashoka S

Ph.D Scholar, Department of

Food Science and Nutrition,

University of Agricultural

Sciences, GKVK, Bengaluru,

Karnataka, India

Shamshad Begum S

Assistant Professor, Department of Food Science and Nutrition,

University of Agricultural

Sciences, GKVK, Bengaluru

Vijayalaxmi KG

Professor, Department of Food

Science and Nutrition,

University of Agricultural

Sciences, GKVK, Bengaluru

Corresponding Author:

Ashoka S

Ph.D Scholar, Department of

Food Science and Nutrition,

University of Agricultural

Sciences, GKVK, Bengaluru,

Karnataka, India

\section{Byproduct utilization of watermelon to develop watermelon rind flour based cookies}

\author{
Ashoka S, Shamshad Begum S and Vijayalaxmi KG
}

DOI: https://doi.org/10.22271/tpi.2021.v10.i2c.5658

\section{Abstract}

Bakery products are popular among different cross sections of population in India and many bakery products are nutritional and have become important part of diet of the people. Cookies are most popular snack items that are small, usually round and flat made from stiff, sweetened dough, and baked. In the present study, Cookies were developed by incorporating watermelon rind flour at different levels like 10, 20 , and 30 per cent with refined wheat flour and compared with control (100\% refined wheat flour). The sensory scores revealed that the overall acceptability of cookies with $30 \%$ incorporation had good acceptable score (8.23) whereas for control cookies sensory score was (8.04). The nutrient composition of best accepted cookies had protein $(4.68 \mathrm{~g})$, fat $(30.04 \mathrm{~g})$, crude fibre $(3.25 \mathrm{~g})$ and carbohydrate $(45.69 \mathrm{~g})$. Also, cookies had good amount of calcium, iron and phosphorous i.e. $43.11 \mathrm{mg}, 2.30 \mathrm{mg}$, and $71.81 \mathrm{mg}$ respectively per $100 \mathrm{~g}$ of cookies. Hence watermelon rind flour which is nutritious by-product of watermelon can be utilized in bakery products to upscale the nutritional profile.

Keywords: watermelon rind, cookies, bakery products, by-product

\section{Introduction}

Fruits and vegetables being perishable in nature undergo spoilage at various stages of their harvesting, handling, transport, storage, marketing, processing. The spoilt produce is not fit for marketing and is a virtual loss. Some fruits do not find much suitability for processing and are mostly used for direct consumption, one such fruit is watermelon (Bhatnagar 1991) ${ }^{\text {[2] }}$ Watermelon belongs to the family of cucumber (Cucurbitaceae) with a large, oval, round or oblong shape. During hot and dry summer this fruit has preferred attraction of common man on an account of its cool- refreshing and pleasing taste and attractive red colour. Watermelon is an excellent source of vitamin $\mathrm{C}$ and a very good source of vitamin $\mathrm{A}$ and a significant amount of vitamin $\mathrm{B}_{6}$ and vitamin $\mathrm{B}_{1}$ and minerals like iron, potassium, magnesium, and phosphorus.

Watermelon biomass can be categorized as four major components which are the pulp, seeds, peel, and rind. The pulp, seeds, and rind constituted approximately $66.16 \%, 1.04 \%, 3.35 \%$ and $29.43 \%$ of the total fruit weight. People eat watermelon pink portion and throw away the rind to the dustbin. But the watermelon rind is nutritive. It has protein, fat, carbohydrates, crude fiber and ash content decently (Koocheki et al., 2007) ${ }^{[4]}$. Finding a use for it also helps to cut down on the amount of garbage and it's good for the environment as well. Watermelon rind can be converted into the value-added product by drying and can also be used for the preparation of bakery products with the supplementation of rind powder very easily.

Bakery products have become popular among different cross sections of population in India in recent years due to increased demand for convenient foods. Many bakery products are nutritive and have become important part of diet of the people. Bread and biscuits have become most popular breakfast of most of the families not only in India but all over the world. India has a large market for the bakery products and is growing rapidly. In the present era growing demand for the bakery products has become one of the most important necessities in the life of the people (Mushtari Begum et al., 2017) ${ }^{[7]}$.

Bakery products, specifically cookies are considered as the most viable and acceptable carriers of supplements (Dhingra et al., 2012) ${ }^{[3]}$. Wheat flour being the base material of cookies although is a good source of carbohydrates however; it may lack appreciable concentrations of fiber, minerals and biomolecules like antioxidants to meet the growing nutritional demands of the vulnerable populations. 
Supplementing flour for making cookies though raises concerns with regard to consumer's acceptability for color, taste, texture and other baking characteristics (Kulkarni \& Joshi, 2013) ${ }^{[3]}$. Based on the nutritional and health benefits of watermelon rind, the present work has been undertaken to study the "Development of cookies by utilization of watermelon rind flour".

\section{Materials and Methods}

The present investigation was carried out at Department of Food Science and Nutrition, University of Agricultural Sciences, Bangalore.

\section{Selection and Collection of Sample}

The fresh and matured watermelon fruits were procured from the local market of Bengaluru, Karnataka, India.

\section{Processing and Dehydration}

The watermelon fruits were washed under running tap water and they were wiped using a clean dry cloth. All the watermelon fruits were peeled separately by using a peeler and the pulp was separated from watermelon rind by using a knife and the remaining portion of seeds were separated by cutting the pulp into small cubes. After weighing the watermelon rind, the pieces were kept for dehydration at 60 ${ }^{\circ} \mathrm{C}$ until it dried properly. The dried rind was ground into powder by using an electric grinder and sieved through a scientific sieve. Then, the dehydrated powder was packed and used for further purpose.

\section{Formulation of watermelon rind cookies}

The cookies were prepared by using watermelon rind flour with refined wheat flour. Three variations of cookies were developed by incorporating a rind flour at different variations like $(10 \%, 20 \%$, and $30 \%)$ and compared with control.

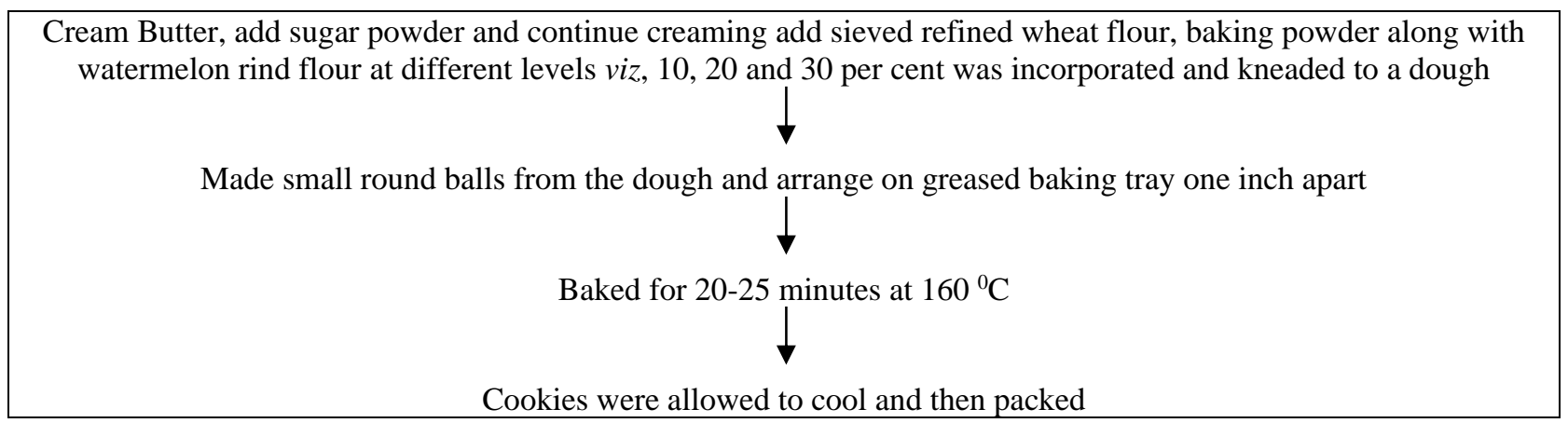

Fig 1: Procedure for preparation of watermelon rind flour cookies

\section{Organoleptic evaluation of the developed products}

The products were subjected to sensory evaluation. Sensory quality attributes were evaluated by a panel of 21 semi-trained members using a nine-point hedonic scale [Amerine et al. (1965)] ${ }^{[1]}$. The products were evaluated for their appearance, color, texture, flavor, taste and overall acceptability.

\section{Computation of nutritional composition for best accepted cookies}

The nutrient composition for the best accepted products was computed by using Indian food composition table Longvah et al. $(2017)^{[6]}$.

\section{Statistical analysis}

The data were subjected to analysis of variance (ANOVA) for testing the significance of variation by using the statistics i.e. software Statistical Package for Social Sciences (SPSS) version 12.0 (Sabine and Brian, 2004) ${ }^{[10]}$.

\section{Results and Discussion \\ Sensory evaluation of the cookies}

Sensory evaluation of the cookies was carried out by 21 semitrained sensory panellists on a nine-point hedonic scale. Attributes like appearance, texture, colour, flavour, taste, and overall acceptability were scored based on its intensity scaled. The result of the sensory analysis is presented in Table 1 . Cookies prepared with variation of 30 percent incorporation had good acceptable sensory score for appearance (8.19), texture (8.14), colour (8.04), flavour (7.95), taste (8.04) and overall acceptability (8.23), when compared to control with 8.00 (appearance), 7.76 (texture), 7.90 (colour, flavour and taste) and 8.04 (overall acceptability). Statistically, increased in overall acceptability was observed from 7.95 at 10 percent incorporation and 8.23 at 30 percent incorporation.

Table 1: Sensory evaluation of watermelon rind flour cookies

\begin{tabular}{|c|c|c|c|c|c|c|}
\hline Variation & Appearance & Texture & Colour & Flavour & Taste & OA \\
\hline C & $8.00 \pm 0.94$ & $7.76 \pm 1.26$ & $7.90 \pm 0.94$ & $7.90 \pm 0.94$ & $7.90 \pm 0.70$ & $8.04 \pm 0.86$ \\
\hline T1 & $8.14 \pm 0.72$ & $7.61 \pm 0.66$ & $8.04 \pm 0.74$ & $7.90 \pm 0.62$ & $7.76 \pm 0.70$ & $7.95 \pm 0.80$ \\
\hline T2 & $7.57 \pm 0.81$ & $7.28 \pm 0.78$ & $7.61 \pm 0.80$ & $7.57 \pm 0.81$ & $7.80 \pm 0.87$ & $7.66 \pm 0.79$ \\
\hline T3 & $8.19 \pm 0.81$ & $8.14 \pm 0.72$ & $8.04 \pm 0.80$ & $7.95 \pm 0.86$ & $8.04 \pm 0.80$ & $8.23 \pm 0.76$ \\
\hline Mean \pm SD & $7.97 \pm 0.84$ & $7.70 \pm 0.92$ & $7.90 \pm 0.83$ & $7.83 \pm 0.81$ & $7.88 \pm 0.76$ & $7.97 \pm 0.82$ \\
\hline F value & NS & $*$ & NS & NS & NS & NS \\
\hline CD & - & 0.54 & - & - & - & - \\
\hline SEM & 0.18 & 0.19 & 0.18 & 0.17 & 0.16 & 0.17 \\
\hline
\end{tabular}

Note: C- Plain or control cookies, T1 $=10 \% \mathrm{WRF}, \mathrm{T} 2=20 \% \mathrm{WRF}, \mathrm{T} 3=30 \% \mathrm{WRF}$

OA-Overall acceptability, NS-Non significant, *-Significant 
Mushtari Begum et al., (2017) ${ }^{[7]}$ conducted a study to prepare finger millet-based chocolate biscuits and the sensory results revealed that all the sensory characteristics like appearance, texture, flavour and overall acceptability showed higher scores compared with control. With respect to above study, the results obtained from present study is also showing $30 \%$ incorporated cookies had higher sensory scores compared to control.

Olaitan et al. (2017) [9] studied watermelon rind flour Supplementation on the quality of wheat-based cookies and the results showed no significant $(p<0.05)$ difference in appearance, texture, and flavour but sample with $2.5 \%$ incorporated was the most acceptable among the blends of wheat and watermelon rind flour cookies. Compared to this study, the results obtained from the present study indicated there was a significant difference with respect to texture and it might be due to the amount of crude fibre present in the watermelon rind flour that altered the texture, whereas no significant difference was observed with respect to appearance, colour, flavour, taste and overall acceptability respectively.

Shamshad Begum S and Suresha S.V., (2016) ${ }^{[8]}$ explored nutri-rich amla to prepare value added products from the residue left after amla juice extraction i.e. amla fibre in baked products like Biscuit, cookies and cakes too. And the results revealed that all amla products were found to be highly acceptable among the subjects. Compared to this study, the results obtained from the present study was same because even though watermelon rind has more fibre it was accepted by the panelists with higher sensory scores.

\section{Nutrient composition of experimental and best accepted WRF cookies (per 100g) *}

The results show that the proximate composition of best accepted WRF cookies contains moisture (12.18\%), protein $(4.68 \%)$, fat $(30.04 \mathrm{~g})$, ash $(1.77 \mathrm{~g})$, crude fibre $(3.25 \mathrm{~g})$ and carbohydrate $(45.69 \mathrm{~g})$ for per $100 \mathrm{~g}$ of cookies. Whereas control cookies contain moisture(12.07\%), protein (4.71g), fat $(29.82 \mathrm{~g})$, ash $(0.23 \mathrm{~g})$, crude fibre $(1.25 \mathrm{~g})$ and carbohydrate $(49.55 \mathrm{~g})$ for per $100 \mathrm{~g}$ of cookies.

The estimated mineral values of best accepted WRF cookies showed that the control cookies had a lower amount of calcium $(11.19 \mathrm{mg})$, iron $(0.80 \mathrm{mg})$ and phosphorous $(50.20 \mathrm{mg})$ compared to 30 percent WRF incorporated cookies i.e., it contains calcium $(43.11 \mathrm{mg})$, iron $(2.30 \mathrm{mg})$ and phosphorous $(71.81 \mathrm{mg})$ respectively. The difference in mineral composition might be because watermelon rind flour contains more amount of minerals than refined wheat flour.

Table 2: Nutrient composition of experimental and best accepted WRF cookies (per 100g)

\begin{tabular}{|c|c|c|c|c|c|c|c|c|c|c|}
\hline Products & & Moisture (\%) & Protein $(\mathbf{g})$ & Fat $(\mathbf{g})$ & Ash (g) & Crude fibre (g) & CHO (g) & Ca (mg) & Fe (mg) & P (mg) \\
\hline \multirow{2}{*}{ Cookies } & Control & 12.07 & 4.71 & 29.8 & 0.23 & 1.25 & 49.55 & 11.19 & 0.80 & 50.20 \\
\cline { 2 - 11 } & Experimental (30\% WRF) & 12.18 & 4.68 & 30.0 & 1.77 & 3.25 & 45.69 & 43.11 & 2.30 & 71.81 \\
\hline
\end{tabular}

Olaitan et al. (2017) ${ }^{[9]}$ conducted a study on the effect of watermelon rind flour supplementation on the quality of wheat-based cookies. The result showed that the moisture content increased from 9.57 per cent (control) to 11.64 per cent $(7.5 \% \mathrm{WRF})$. The result also showed a decrease in dry matter from 90.43 per cent (control) to 88.37 per cent $(7.5 \%$ WRF). There was an increase in crude protein (9.79 to $15.35 \%$ ) which helps to improve the nutritional quality of the cookies, crude fibre (0.86 to $1.66 \%)$, fat (8.38 to $13.12 \%)$, ash (1.43 to $3.16 \%)$ and a decrease in carbohydrate (69.96 to $55.07 \%$ ) showing the watermelon rind flour has low carbohydrate content. The minerals of iron have been increased from 31.56 per cent (control) to 48.22 per cent (7.5\% WRF), calcium from 42.63 per cent (control) to 172.70 per cent $(7.5 \% \mathrm{WRF}$ ) and phosphorous from 175.40 per cent (control) to 341.50 per cent $(7.5 \% \mathrm{WRF})$.

Table 3: Production cost of watermelon rind cookies (per 100g)

\begin{tabular}{|c|c|c|c|c|}
\hline $\begin{array}{l}\text { Sl. } \\
\text { No. }\end{array}$ & Ingredients & $\begin{array}{c}\text { Amount } \\
\text { (Rs.) }\end{array}$ & $\begin{array}{c}\text { Quantity } \\
(\mathrm{g} / \mathrm{ml})\end{array}$ & Cost (Rs.) \\
\hline 1 & Maida & $40 / 1 \mathrm{Kg}$ & 31.85 & 1.27 \\
\hline 2 & Watermelon rind flour & - & 13.65 & - \\
\hline 3 & Sugar & $40 / 1 \mathrm{Kg}$ & 15.92 & 0.63 \\
\hline 4 & Butter & $40 / 100 \mathrm{~g}$ & 36.4 & 14.6 \\
\hline 5 & Vanilla essence & $22 / 20 \mathrm{ml}$ & 1 & 1.1 \\
\hline 6 & Baking powder & $20 / 50 \mathrm{~g}$ & 1 & 0.5 \\
\hline & Total & & 100 & 18.1 \\
\hline & rerhead charges@30\% & & & 5.4 \\
\hline & Profit (15\%) & & & 2.7 \\
\hline & Cost of the product & & & 26.24 \\
\hline & & & \multicolumn{2}{|c|}{ Round off to Rs. 26.00} \\
\hline
\end{tabular}

The cost of preparation for a watermelon rind cookie with many other ingredients were calculated per $100 \mathrm{gm}$ of the product. Overhead charges at the rate of $30 \%$ of expenditure on manufacturing which comprises labour cost, depreciation cost, and equipment, etc. and profit of 15 per cent was included. It indicated that the cost of cookies was Rs.26.50 per $100 \mathrm{~g}$.

\section{Conclusion}

It can be concluded from results that the incorporation of watermelon rind flour in cookies can improve the nutritional quality of crude fibre, calcium, iron and phosphorous of product and also add variety to the diet. The prepared cookies were found to be acceptable in both sensory and nutritional quality. Thus, watermelon rind flour can partially replace the refined wheat flour which can be a best novel product.

\section{References}

1. Amerine MA, Pangborn RM, Roseller EB. Principles of Sensory evaluation of food. Academic press, New York, 1965.

2. Bhatnagar DK. Utilization of watermelon rind for jam making. Indian Food Packer 1991;45(1):46-48.

3. Dhingra D. Michael M. Rajput H and Patil RT. Dietary fibre in foods: A review. Journal of food science and technology 2012;49(3):255-266.

4. Koocheki A. Razavi SMA. Milani E. Moghadam TM. Abedini M. Alamatiyan S et al. Physical properties of watermelon seed as a function of moisture content and variety. Int. Agrophysics 2007;21:349-359.

5. Kulkarni AS, Joshi DC. Effect of replacement of wheat flour with pumpkin powder on textural and sensory qualities of biscuit. International Food Research Journal 2013;20(2):587.

6. Longvah T, Anantan I, Bhaskarachary K, Venkaiah K. Indian food composition tables. Hyderabad: National 
Institute of Nutrition, Indian Council of Medical Research, 2017.

7. Mushtari Begum J, Shamshad Begum S, Anupama Pandey, Shivaleela HB. Finger millet as a nutritional ingredient in bakery products. Contemporary Research in India 2017;7(2):96-100.

8. Shamshad Begum S, Suresha SV. Value added nutri-rich Amla products for good nutrition, health and empowerment (OPCND-15), Published in the proceedings of International conference on Food, Nutrition and Health 2016(ICFNH-2016);06.06.2016 to 08.06.2016 at Fortune Pandiyan Hotel, Madurai, PP: 61.

9. Olaitan NI, Eke MO, Agudu SS. Effect of watermelon (Citrullus Lantus) rind flour supplementation on the quality of wheat-based cookies. The International Journal of Engineering and Sciences 2017;6(12):38-44.

10. Sabine L, Brian SE. A hand book of statistical analysis using SPSS. Print United States of America, 2004. 